\title{
Energy Analysis and Exergy Utilization in the Residential Sector of Cameroon
}

\author{
Talla Konchou Franck Armel ${ }^{1,2^{*}}$, Aloyem Kazé Claude Vidal2,3, Tchinda René ${ }^{2}$ \\ ${ }^{1}$ Environmental Energy Technologies Laboratory (EETL), University of Yaounde I, Yaounde, Cameroon \\ ${ }^{2}$ LISIE, University Institute of Technology Fotso-Victor, University of Dschang, Bandjoun, Cameroon \\ ${ }^{3}$ HTTTC, Department of Electrical and Power Engineering/FSC, University of Bamenda, Bamenda, Cameroon \\ Email: ${ }^{*}$ tkfarmel@yahoo.fr
}

Received 1 March 2015; accepted 17 March 2015; published 25 March 2015

Copyright (C) 2015 by authors and Scientific Research Publishing Inc.

This work is licensed under the Creative Commons Attribution International License (CC BY).

http://creativecommons.org/licenses/by/4.0/

(c) (i) Open Access

\begin{abstract}
In this paper, we present an analysis of energy and exergy utilization in the residential sector of Cameroon by considering the sectoral energy and exergy flows for the years of 2001-2010. Exergy analysis of Cameroon residential sector utilisation indicates a less efficient picture than that obtained by the energy analysis. Cooking stands out as the most inefficient end use in the Cameroon's residential sector. In 2010, the energy and exergy efficiency are determined and were respectively $58.74 \%$ and $22.63 \%$. Energy and exergy flows diagrams for the overall efficiencies of Cameroon residential sector are illustrated and a comparison with the residential sector of other countries is also done. To carry out this study, a survey of 250 households was conducted and the sharing of the end uses of energy was done and data were gathered.
\end{abstract}

\section{Keywords}

Exergy, Efficiency, Energy Flow, Residential Sector

\section{Introduction}

The search for better living conditions has pushed the country to develop new areas of research including that of energy management, and the optimization of energy use. Thus today the industrialization of a country is determined by the rational and efficient use of energy. It has been observed that in Cameroon, the use of energy has taken on a new dimension this can be explained by the growing population (which increases energy requirements) for the past decade, and also by the government policy that wants to raise the rank of Cameroon an emerging country in 2035. Thus the consumption of wood energy, fuel and electricity continue to rise, so it will be wise to reconcile high population growth, government projects and the efficient and rational use of energy. In

"Corresponding author. 
2010, energy consumption in Cameroon was estimated to 5722.22 kilo Ton Oil Equivalent (TOE) [1]. In the same year, the residential sector represented approximately $70 \%$ of the total Cameroon energy consumption [1]. World-wide residential sector consumes about $17 \%-70 \%$ of the total energy as can be seen in Table 1 [2].

From the first law of thermodynamics, it is clear that energy is conserved. The first law tells us only about the amount of energy that is put into play, and it takes into account only the internal parameters in the system, thus neglecting external parameters and the external environment to the system. Following these imperfections, it was introduced a new concept that will not only study the quality of energy used, but will take into account external parameters to the system: it is exergy. The analysis based on exergy was based on the two principles of thermodynamics hence its complexity and efficiency. Nowadays, exergy analysis is the best tool in the analysis of the efficiency of a system [3].

This concept has been used for the first time by Reistad (1975) [4]. He applied it in the economic analysis of US in 1970. Several studies have been done in the same vein and have been applied indifferent countries, including Italy [5], Turkey [6], the UK [7], Norway [8] China [9] and Saudi Arabia [10]-[12]. Other researches in the residential sector were made in Malaysia [2], Turkey [13] Jordan [14].

Energy and exergy analysis is an important approach to identify the various losses and determine the specific sector with low energy efficiency, which is necessary to find new ways to improve the efficiency of energy.

The primary objective of this work is to determine the overall energy and exergy efficiency of the residential sector in Cameroon from 2001 to 2010, then we will discuss the residential sector Cameroonians compare to other countries in this literature.

\section{Methods}

The methodology adopted in this study was first used by Dincer et al. [9], who applied Resitad's approach [3].

\subsection{Exergy Calculation}

In this section, we will discuss some basic quantities and mathematical relations to exergy analysis.

\subsubsection{Chemical Exergy}

One of the most common mass flows is hydrocarbon fuels at near-ambient conditions, for which the specific exergy reduces to chemical exergy and can be written as follows [2]:

$$
\varepsilon_{r \gamma}=\gamma_{r \gamma} H_{f f}
$$

where $\gamma_{f f}$ denotes the fuel exergy grade function, defined as the ratio of fuel chemical exergy. Table 2 ([15][17]) shows typical values of $H_{f f}, \varepsilon_{f f}$ and $\gamma_{f f}$ for the fuels encountered in the present study. As shown in this table, all the values of the exergy grade function are very close to unity.

Ertesvag and Mielnik [7] and Erstesvag [13] reported that the major parts of the input to the system are fuel and other energy carriers. For mechanical and electrical energy, the exergy content is equal to the energy content. Exergy factors for different energy carriers are shown in Table 3.

Table 1. Worldwide residential energy consumption.

\begin{tabular}{ccccccccccccc}
\hline & Sweden & Italy & USA & UK & Canada & Mexico & Japan & Malaysia & Jordan & Cameroon \\
\hline Percentage & $19 \%$ & $17 \%$ & $25 \%$ & $31 \%$ & $24 \%$ & $23 \%$ & $22.60 \%$ & $19 \%$ & $29 \%$ & $70 \%$ & $29 \%$ \\
\hline
\end{tabular}

Source: Saidur et al., 2007.

Table 2. Properties of selected fuels.
\begin{tabular}{cccc}
\hline \multicolumn{4}{c}{} \\
\hline Fuel & $H_{f}(\mathrm{kj} / \mathrm{kg})$ & $\varepsilon_{f}(\mathrm{kj} / \mathrm{kg})$ & $\gamma_{f}$ \\
\hline Diesel & 44.800 & 42.265 & 0.943 \\
Butane & 49.463 & 48.272 & 0.976 \\
\hline
\end{tabular}


Table 3. Exergy factors of energy carriers.

\begin{tabular}{cc}
\hline Energy carriers & Exergy factors \\
\hline Waterfall anergy & 1 \\
Electrical energy & 1 \\
Oil, petroleum products & 1.06 \\
LPG & 1.06 \\
Coal & 1.06 \\
Diesel oil & 1.07 \\
Fuel wood (20\% humidity) & 1.11 \\
\hline
\end{tabular}

\subsubsection{Energy and Exergy Efficiencies}

In this study, the expression of the energy $(\eta)$ and the exergy $(\psi)$ efficiencies for the principle type of processes are based on the following definitions [2]:

$$
\begin{gathered}
\eta=\left(\frac{\text { energy in product }}{\text { total energy input }}\right) \times 100 \% \\
\psi=\left(\frac{\text { exergy in product }}{\text { total exergy input }}\right) \times 100 \%
\end{gathered}
$$

\subsubsection{Heating and Cooling Process}

Electric process is taken to generate product heat $Q_{p}$ at the constant temperature $T_{p}$ either from electrical energy $W_{e}$. The energy and exergy efficiencies for electrical heating are [9].

$$
\begin{gathered}
\eta_{h, e}=\frac{Q_{p}}{W_{e}} \\
\psi_{h, e}=\frac{E^{Q_{p}}}{E^{W_{e}}}=\frac{\left[1-\left(T_{0} / T_{p}\right) Q_{p}\right]}{W_{e}} \\
\psi_{h, e}=\left(1-\frac{T_{0}}{T_{p}}\right) \eta_{h, e}
\end{gathered}
$$

\subsection{Methodology and Data Sources}

In order to determine the energetic and exergetic output of Cameroon's residential sector, it is essential to know how this energy is used in this sector. Therefore, we have used the data of two institutions namely the National Statistical Institute (NSI) and the Ministry of Energy and Water Resource. Then, a further survey was carried out on 250 households of different locations and different living standards in Cameroon. The aim of this survey was to collect necessary data for the realization of this work. It was carried out by the students of the Analysis Laboratory of Technologies of Energy and Environment (ALTEE). The questionnaire used covered the following aspects:

- Types of appliances functioning with fuel.

- Information detailed over the electrical appliance, their powers, numbers, and the utilization time.

- Types of appliances used in cooking.

- Types of lighting and its utilization time and power rating.

In all questions, the level of ownership was being asked for each type of equipment and appliance. To ensure the good quality of such a survey, the students were given a tutorial lecture on how to collect and record the required data correctly and efficiently. At the end of the survey, the sharing of the end uses of electrical energy was determined. 


\subsection{Energy and Exergy Efficiency of Electrical Appliances}

Each appliance operates in a range of efficiencies. The efficiency of an appliance is usually described in terms of energy only. But there we add another term called exergy efficiency that correlates the second law of thermodynamics [14]. The reference temperature $T_{0}$, appliances energy efficiency $\eta_{e}$, and its product temperature $T_{p}$, are needed to get the exergy efficiency and these values are presented in Table 4.

If electrical or mechanical energy is output, the following equation is valid since the quality factor of both energy forms is equal to one based on Utlu and Hepbasli [18]

Exergy efficiency

$$
\psi=q_{\text {elec }} \times W_{\text {elec(Mech })} /(\text { Mech }) / q_{\text {elec }} \times W_{\text {elec }}=\text { energy efficiency, } \eta
$$

The exergy efficiency of some of refrigerator-freezer has been calculated with the aid of methodologies described by Dincer et al. [9] and Utlu and Hepbasli [19].

\subsection{Energy and Exergy Efficiency of a Cooking Appliance}

Using the methodology describe in Section 2.1, the exergy efficiency for this appliance can be calculated using following known values:

- Energy efficiency, $\eta_{f}=65 \%$.

- Reference temperature, $T_{o}=298 \mathrm{~K}$.

- Product temperature, $T_{p}=374 \mathrm{~K}$.

These values are needed in calculating the overall energy and exergy efficiencies.

\subsection{Weighted Mean Energy and Exergy Efficiencies}

Weighted mean energy and exergy efficiencies are calculated for the residential sector using a three-step process.

\subsubsection{Weighted Mean Electrical Energy an Exergy Efficiencies (First Step)}

First, weighted means are obtained for the electrical energy and exergy efficiencies for the device categories listed in Table 4, where the weighting factor is the ratio of electrical energy input to the device category to the total electrical energy input to all device categories in the sector [2].

The calculation of the overall weighted mean energy and exergy can be illustrated as follows:

$$
R_{\eta_{e}}=\frac{\left(e_{\text {Fluorescent light }} \times \eta_{\text {Fluorescent light }}\right)+\left(e_{T V} \times \eta_{T V}\right)+\cdots+\left(e_{\text {Radio player }} \times \eta_{\text {Radio player }}\right)}{e_{\text {Fluorescent light }}+e_{T V}+\cdots+e_{\text {Radio player }}}
$$

where $R_{\eta_{e}}$ is the weighted mean energy efficiency, $e_{\text {appliance }}$ is the appliance's energy consumption, $\eta_{\text {appliance }}$ the appliance's energy efficiency.

\begin{tabular}{|c|c|c|c|c|c|}
\hline Appliances & $\eta_{e} \quad(\%)$ & $T_{p} \quad(\mathrm{~K})$ & $T_{o} \quad(\mathrm{~K})$ & $\psi_{e} \quad(\%)$ & Share of used energy (\%) \\
\hline Fluorescent light & 12.50 & - & - & 11.50 & 35.92 \\
\hline TV & 80 & - & - & 80 & 11.37 \\
\hline Fan & 80 & - & - & 80 & 7.18 \\
\hline Refrigerator-freezer & 60 & 298 & 265 & 7.47 & 23.95 \\
\hline Mobile phone charger (MPC) & 70 & - & - & 70 & 2.40 \\
\hline Personal computer (PC) & 70 & - & - & 70 & 11.94 \\
\hline Radio player & 80 & - & - & 80 & 7.18 \\
\hline Cooking appliances (LPG and diesel oil) & 65 & 298 & 374 & 13.20 & \\
\hline
\end{tabular}

Table 4. Energy efficiency, product and environment temperatures, exergy efficiency and shared of used energy. 


$$
R_{\psi_{e}}=\frac{\left(e_{\text {Fluorescent light }} \times \psi_{\text {Fluorescent light }}\right)+\left(e_{T V} \times \psi_{T V}\right)+\cdots+\left(e_{\text {Radio player }} \times \psi_{\text {Radio player }}\right)}{e_{\text {Fluorescent light }}+e_{T V}+\cdots+e_{\text {Radio player }}}
$$

where $R_{\psi_{e}}$ is the weighted mean exergy efficiency, $e_{\text {appliance }}$ is the appliance's energy consumption, $\psi_{\text {appliance }}$ the appliance's exergy efficiency.

\subsubsection{Overall Weighted Means Energy and Exergy Efficiencies (Third Step)}

Third, overall weighted means are obtained for the energy and exergy efficiencies for the electrical and fossil fuel processes, where the weighting factor is the ratio of total fossil fuel or electrical energy input to the residential sector to the total energy input to the sector [2].

Weighting factor for electrical energy can be calculated using following equation:

$$
W F_{e}=\frac{\sum e}{\sum e+\sum f}
$$

$W F_{e}$ is the overall weighting factor for electrical energy, $\sum e$ the overall electrical energy consumption, and $\sum f$ the overall fossil fuel energy consumption.

Similarly weighting factor for fossil fuel can be calculated using following equation:

$$
W F_{f}=\frac{\sum f}{\sum e+\sum f}
$$

Finally, using the following equation, the overall weighted energy and exergy can be calculated as:

$$
R_{\eta_{o}}=\left(R_{\eta_{e}} \times W F_{e}\right)+\left(R_{\eta_{f}} \times W F_{f}\right)
$$

where $R_{\eta_{o}}$ is the overall energy efficiency, $R_{\eta_{e}}$ is the weighted mean electrical energy efficiency, and $R_{\eta_{f}}$ the weighted mean fossil fuel energy efficiency.

$$
R_{\psi_{o}}=\left(R_{\psi_{e}} \times W F_{e}\right)+\left(R_{\psi_{f}} \times W F_{f}\right)
$$

where $R_{\psi_{o}}$ is the overall exergy efficiency, $R_{\psi_{e}}$ is the weighted mean electrical exergy efficiency, and $R_{\psi_{f}}$ the weighted mean fossil fuel exergy efficiency.

\section{Results and Discussion}

\subsection{Electrical Energy and Exergy Calculation}

Using the sharing of energy in the residential sector, the energy consumption in the residential sector is given in Table 5.

Table 5 shows a significant growth in the consumption of electrical energy. That is simply due to the growing demand of the population. It is important to note that much of the Cameroonian population is still without access to electricity. Indeed according to the National Institute of Statistics in 2005, 49.7\% of the population has access to electricity; this figure rose to $60 \%$ in 2010 due to the expansion and intensification of the power grid efforts. Between 2001 and 2010, access to electricity rate increased nationally and in urban areas. But there was a slight decline in rural areas. This may be due to the fact that the number of households increases without that new subscribers will have the same pace because households are more likely to subscribe to electricity from a neighbour than from AES Sonel.

\subsection{Fossil Fuel Energy and Exergy Use}

In Cameroon, the residential sector mainly uses Liquefied Petroleum Gas (LPG) and diesel oil as their fuel for cooking, while electrical energy is rarely utilized. Their energetic and exergetic consumptions are given in Table 6. It is important to mention that this energy is essentially used by cooking appliances.

It should be noted that the domestic gas consumption is still very low in Cameroon as evidenced by recurrent shortages and limited access especially in rural areas and in the savannah zone of Northern Cameroon. The offer 
Table 5. Total energy and exergy consumption (assuming energy consumption = exergy consumption) in TJ.

\begin{tabular}{ccccccccccc}
\hline Appliances & 2001 & 2002 & 2003 & 2004 & 2005 & 2006 & 2007 & 2008 & 2009 & 2010 \\
\hline Fluorescent light & 689.66 & 732.76 & 786.64 & 898.00 & 977.02 & 1052.45 & 1074.00 & 1156.62 & 1167.40 & 1275.16 \\
TV & 218.30 & 231.98 & 249.00 & 284.25 & 309.26 & 333.14 & 339.96 & 366.11 & 369.52 & 403.63 \\
Fan & 137.85 & 146.67 & 157.24 & 179.50 & 195.29 & 210.37 & 214.68 & 231.19 & 233.35 & 254.89 \\
Refrigerator-freezer & 459.84 & 488.58 & 524.50 & 598.75 & 651.44 & 701.73 & 716.10 & 771.19 & 778.37 & 850.22 \\
MPC & 46.08 & 48.96 & 52.56 & 60.00 & 65.28 & 70.32 & 71.76 & 77.28 & 78.00 & 85.20 \\
PC & 229.82 & 244.18 & 262.14 & 299.25 & 325.58 & 350.72 & 357.90 & 385.43 & 389.02 & 424.93 \\
Radio player & 137.85 & 146.67 & 157.24 & 179.50 & 195.29 & 210.37 & 214.68 & 231.19 & 233.35 & 254.89 \\
Total & 1920 & 2040 & 2190 & 2500 & 2720 & 2930 & 2990 & 3220 & 3250 & 3550 \\
\hline
\end{tabular}

Table 6. Total fossil fuel energy consumption (TJ).

\begin{tabular}{|c|c|c|c|c|c|c|c|c|c|c|}
\hline & 2001 & 2002 & 2003 & 2004 & 2005 & 2006 & 2007 & 2008 & 2009 & 2010 \\
\hline Butane energy & 1920 & 2040 & 2190 & 2500 & 2720 & 2930 & 2990 & 3220 & 3250 & 3550 \\
\hline Oil energy & 5600 & 5780 & 6710 & 6350 & 5600 & 5660 & 5340 & 5180 & 5180 & 5240 \\
\hline Total energy & 7520 & 7820 & 8900 & 8850 & 8320 & 8590 & 8330 & 8400 & 8430 & 8790 \\
\hline Total exergy & 7898.30 & 8210.40 & 9355.10 & 9279.90 & 8698 & 8965.70 & 8683.90 & 8741.10 & 8770.60 & 9132.50 \\
\hline
\end{tabular}

is limited today by subsidized and administered system in one hand and by structural problems (lack of storage capacity, lack of security stocks, high cost of equipment for primary consumption, low interchangeability packaging system, etc.). According to the HSPC, such provision of LPG increased by 9\% between 2010 and 2011.

The consumption of oil has increased from 5600 TJ in 2001 to 5240 TJ in 2010, a decrease of approximately $34 \%$. This decline has been observed since 2003. This may be explained by the increase in prices of petroleum products and the increase in electrified rural areas. This continuous decline in consumption of kerosene causes a change in the structure of consumption of petroleum products by households.

\subsection{Energy and Exergy Efficiencies}

\subsubsection{Energy and Exergy Efficiencies of Electrical Appliances}

Energy and exergy efficiencies of electrical appliances are determined using the methodology stated in Section 2.3. The exergy efficiency depends on the energy efficiency, the environmental temperature and the product temperature. Using the electrical energy efficiencies as inputs, exergy efficiencies $\left(\psi_{e}\right)$ have been determined and presented in Table 4. For example, the exergy efficiency for the refrigerator-freezer appliance is calculated using Equation (6) as follows:

Assuming:

Energy efficiency, $\eta_{e}=60 \%$.

Reference Temperature, $T_{0}=(273+25) \mathrm{K}=298 \mathrm{~K}$.

Product temperature, $T_{p}=(273-8) \mathrm{K}=265 \mathrm{~K}$.

Then, exergy efficiency is calculated using the following formula

$$
\psi_{e}=\left(1-\frac{T_{0}}{T_{p}}\right) \eta_{e}=\left(1-\frac{265}{298}\right) \times 60=7.47 \%
$$

The calculation of the overall energy and exergy efficiencies, $\eta_{0}$ and $\psi_{0}$, respectively, of all appliances can be done using the share or percentage use of each appliance in the total used energy as a weighting factor.

$$
\eta_{0}=\sum_{i} \eta_{e i} \times F_{e i} / 100
$$




$$
\psi_{0}=\sum_{i} \psi_{e i} \times F_{e i} / 100
$$

where $\eta_{e i}$ and $\psi_{e i}$ are the energy and exergy efficiencies of appliance $i(\%), F_{e i} i$ the fractional energy usage for appliance $i(\%)$. Applying these equations, the overall weighted energy and exergy efficiencies for all appliances are $70.24 \%$ and $50.61 \%$, respectively.

\subsubsection{Energy and Exergy Efficiencies of a Cooking Appliance}

Energy and exergy efficiencies of cooking appliances have been calculated using the input data shown in Section 2.4 and Equations (10) and (11) and presented in Table 4.

\subsubsection{Energy and Exergy Efficiencies of Lighting}

According to the survey, lighting electrical consumption in Cameroon is found to be divided approximately between fluorescent and bulb types with their energy and exergy efficiencies are $20 \%$ and $18.5 \%$, and $5 \%$ and $4.5 \%$, respectively [20] [21]. Using these two values, the energy and exergy efficiencies for lighting are calculated and were $12.5 \%$ and $11.5 \%$, respectively.

\subsection{Weighted Mean Energy and Exergy Efficiencies}

The weighted mean energy and exergy efficiencies are calculated using Equations (8) and (9) and shown in Table 7. A sample example for the year 2010 is shown below:

$$
\begin{aligned}
R_{\eta_{e}}= & (1275.16 \times 12.5+403.63 \times 80+254.89 \times 80+850.22 \times 60+85.20 \times 70+424.93 \times 70 \\
& +254.89 \times 80) /(1275.19+403.63+254.89+850.22+85.20+424.93+254.89) \\
= & 49.50 \% \\
R_{\psi_{e}}= & (275.16 \times 11.5+403.63 \times 80+254.89 \times 80+850.22 \times 7.47+85.20 \times 70+424.93 \times 70 \\
& +254.89 \times 80) /(1275.19+403.63+254.89+850.22+85.20+424.93+254.89) \\
= & 36.56 \%
\end{aligned}
$$

\begin{tabular}{|c|c|c|c|c|}
\hline \multirow{2}{*}{ Year } & \multicolumn{2}{|c|}{ Electrical } & \multicolumn{2}{|c|}{ Fossil fuel } \\
\hline & Energy efficiency $R_{\eta_{e}}$ & Exergy efficiency $R_{\psi_{e}}$ & Energy efficiency $R_{n_{t}}$ & Exergy efficiency $R_{y}$ \\
\hline 2001 & 49.50 & 36.56 & 65 & 13.20 \\
\hline 2002 & 49.50 & 36.56 & 65 & 13.20 \\
\hline 2003 & 49.50 & 36.56 & 65 & 13.20 \\
\hline 2004 & 49.50 & 36.56 & 65 & 13.20 \\
\hline 2005 & 49.50 & 36.56 & 65 & 13.20 \\
\hline 2006 & 49.50 & 36.56 & 65 & 13.20 \\
\hline 2007 & 49.50 & 36.56 & 65 & 13.20 \\
\hline 2008 & 49.50 & 36.56 & 65 & 13.20 \\
\hline 2009 & 49.50 & 36.56 & 65 & 13.20 \\
\hline 2010 & 49.50 & 36.56 & 65 & 13.20 \\
\hline
\end{tabular}

\subsubsection{Weighting Factor}

The weighting factors for fossil fuel and electricity is determined by applying Equations (12) and (13) and presented in Table 8. An example for the year 2010 is calculates as follows:

Table 7. Weighted mean electrical and fossil fuel energy and exergy efficiency (\%). 
Table 8. Overall weighting factors for electrical and fossil fuel energy.

\begin{tabular}{lll}
\hline Year & $W F_{e}$ & $W F_{f}$ \\
\hline 2001 & 0.25 & 0.74 \\
2002 & 0.26 & 0.74 \\
2003 & 0.25 & 075 \\
2004 & 0.28 & 0.72 \\
2005 & 0.33 & 0.67 \\
2006 & 0.34 & 0.66 \\
2007 & 0.36 & 0.64 \\
2008 & 0.38 & 0.62 \\
2009 & 0.38 & 0.61 \\
2010 & 0.40 & 0.59 \\
\hline
\end{tabular}

$$
\begin{aligned}
& W F_{e}=\frac{3550}{5240+3550}=0.40 \text { for the electricity } \\
& W F_{f}=\frac{5240}{5240+3550}=0.59 \text { for the fossil fuel }
\end{aligned}
$$

\subsubsection{Overall Energy and Exergy Efficiencies}

Using the Equations (14) and (15), the overall energy and exergy efficiencies are determined and presented in the Figure 1. The example for the year 2010 is illustrated

$$
\begin{aligned}
& \text { Overall energy efficiency }=(49.50 \times 0.40)+(65 \times 0.59)=58.15 \% \\
& \text { Overall exergy efficiency }=(36.56 \times 0.40)+(13.2 \times 0.59)=22.41 \%
\end{aligned}
$$

We note that, exergy efficiency was lower than its corresponding energy efficiency for the years 2001-2010. The most significant differences between energy and exergy efficiencies are attributed to cooking and Refrigerator-freezer.

In Table 9 we classified the end use of energy into three great families (electrical appliances, lighting and cooking). It can be seen that, electrical appliances are the most efficient end uses for energy and exergy utilization. Owing to the fact that most electrical appliances have identical energy and exergy efficiency values since their output is either electrical or mechanical energy (Figure 2).

For the proper utilization of exergy, it is desirable to have a value for $\eta$ as close to unity as practical and also a good match between the supply energy quality and the end use process. Figure 2 shows the energy efficiency, exergy efficiency as well as the ratio between them for different end uses of the residential sector in Cameroon. A proper match is made whenever the value of the energy efficiency/exergy efficiency ratio approaches unity. The inefficient utilization of energy resource is characterized by the higher value [14]. Cooking stands out as the most inefficient end use in the Cameroon's residential sector, due to the large gap between reference temperature (298 K) and product temperature (374 K).

Cameroon is not the only country where the exergy efficiency of his residential sector is lower than the energy efficiency many other researches where made and the same conclusion was done. According to the Table 10, it is observed that the exergy efficiency of the residential sector in Cameroon is higher than in many countries. This can be explained by the standard of living of the Cameroonian population and climate. Indeed because of their standard of living, Cameroonians can not afford some appliances with high exergy loss as rice cooker washing machine and air conditioner. The favorable climate also avoids certain need such as water heating and 


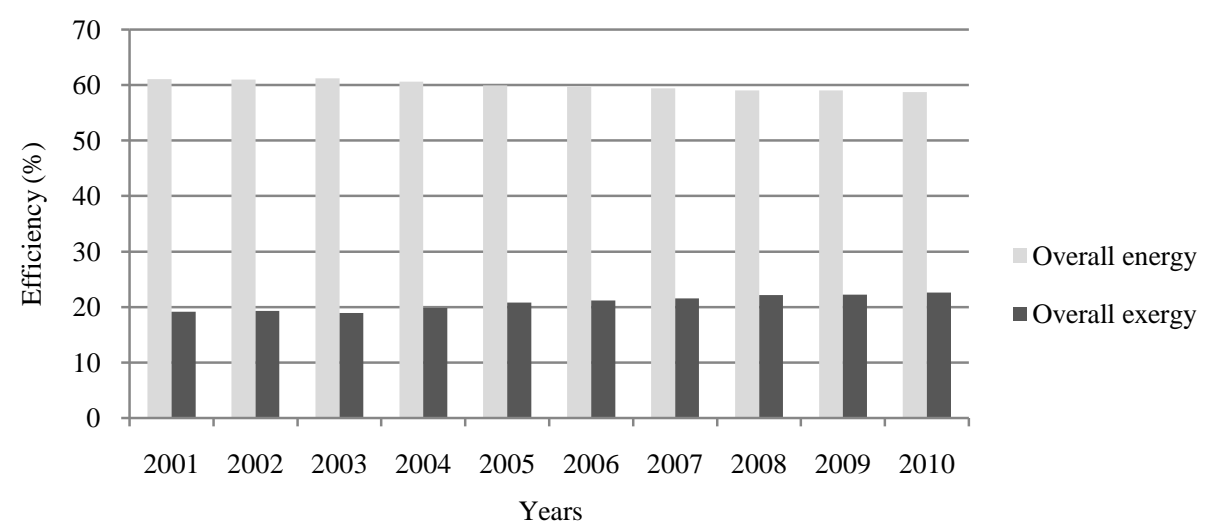

Figure 1. Overall energy and exergy efficiency of residential sector in Cameroon.



Figure 2. Energy efficiency, exergy efficiency for different end uses.

Table 9. Calculated average energy efficiency, exergy efficiency of Cameroon’s residential sector in 2010.

\begin{tabular}{cccc}
\hline End use & $\eta(\%)$ & $\psi(\%)$ & Share (\%) \\
\hline Cooking & 65 & 13.20 & 59.61 \\
Lighting & 12.50 & 11.50 & 14.50 \\
Electrical appliances & 70.24 & 50.61 & 25.87 \\
Total & 58.15 & 22.41 & 100 \\
\hline
\end{tabular}

space heating. These two needs are the main causes of low exergy efficiency in the residential sector in Jordan.

\subsection{Energy and Exergy Products and Losses}

To identify the energy and exergy products and losses, it is relevant to utilize energy and exergy flow. These flow diagrams are also helpful in distinguishing the high or low energy and exergy efficient devices. Based on the result of the analyses presented above, we established the energy and exergy flow diagrams of Cameroon's residential sector for the year 2010. These diagrams are presented in Figure 3 and Figure 4 which show energy and exergy inputs, productions and losses for each end use of the sector.

To raise the exergy efficiency in the residential sector in Cameroon, more actions are undertaken. One of them is the creation in the Ministry of Water and Energy a Sub-Directorate of Energy Management. One of its mission is to promote energy efficiency in the Cameroon territory and thus in his actions, several awareness campaigns are carried out in this direction. 
Table 10. Overall energy and exergy efficiencies at the residential sector of few countries.

\begin{tabular}{ccccc}
\hline Countries & Year & $\begin{array}{c}\text { Overall energy } \\
\text { efficiency (\%) }\end{array}$ & $\begin{array}{c}\text { Overall exergy } \\
\text { efficiency (\%) }\end{array}$ & Reference \\
\hline China & 2005 & - & 10 & {$[8]$} \\
Canada & 1986 & 50 & 15 & {$[7]$} \\
USA & 1970 & 50 & 14 & {$[7]$} \\
Brazil & 2001 & 35 & 23 & {$[7]$} \\
Italy & 1990 & - & 2 & {$[7]$} \\
Malaysia & $1997-2004$ & 69.32 & 29.98 & {$[12]$} \\
Jordan & 2006 & 66.60 & 15.40 & {$[14]$} \\
Turkey & $2004-2005$ & 80.98 & 22.17 & {$[15]$} \\
Norway & 2000 & - & 12 & {$[9]$} \\
Saudi Arabia & 2004 & 76 & 9 & - \\
Cameroon & 2010 & 58.15 & 22.41 & \\
\hline
\end{tabular}

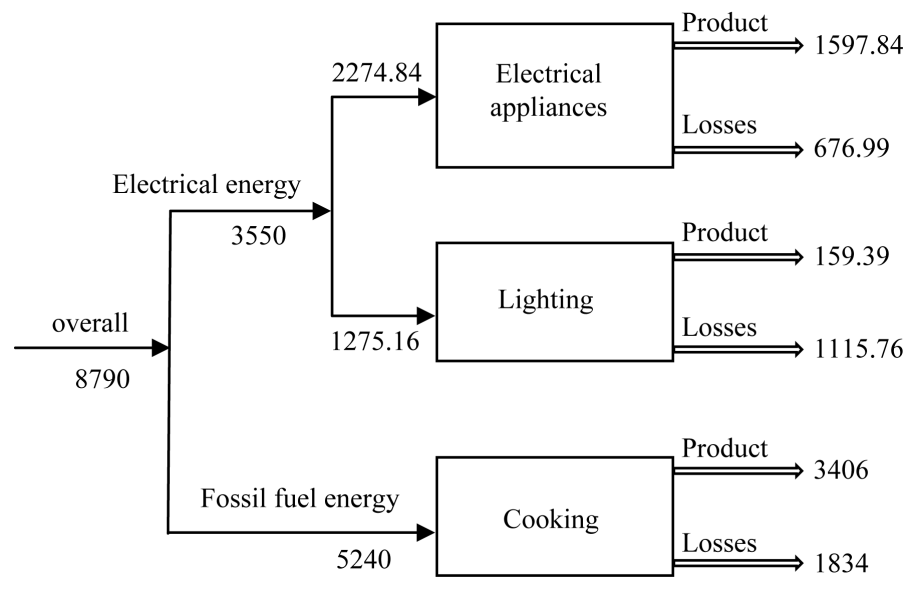

Figure 3. Energy flow (TJ) diagram for the residential sector in Cameroon for the year 2010.

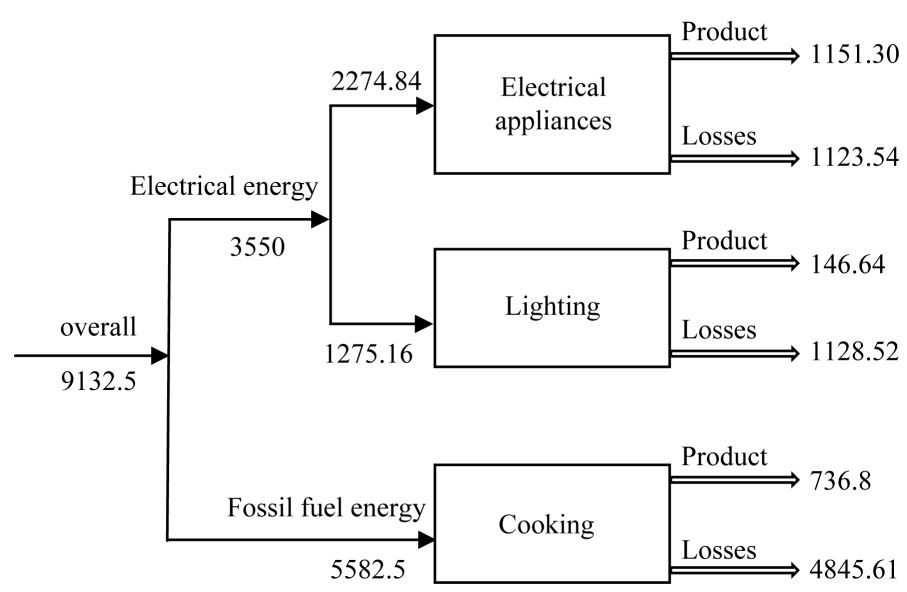

Figure 4. Exergy flow (TJ) diagram for the residential sector in Cameroon for the year 2010. 


\section{Conclusion and Policy Implications}

In this paper, the overall energy and exergy efficiencies of the residential sector in Cameroon for a period of 10 years (2001-2010) have been determined by applying exergy analysis techniques used by Dincer et al. [9]. In 2010, the overall energy efficiency was 58.74\% whereas the overall exergy was 22.63\%. The exergy efficiency appears to be much lower than its corresponding energy efficiency due to the large amount of losses taking place in cooking end use. Analyses in this study have shown that the highest energy and exergy efficient end uses are the electrical appliances while lighting and cooking end uses are the least respectively.

The obtained efficiency values are comparable to those reported in China, Canada, USA, Brazil, Italy, Malaysia, Jordan, Turkey, Norway and Saudi Arabia. The exergy efficiencies of the Cameroon residential sector appear to be higher than those of Saudi Arabian and Norwegian but less than those of Malaysian and Turkish.

The data obtained from the study can be used as a basis for calculating cost benefit analysis for the implementation of new renewable sources for electricity generation and developing an emission abatement program in Cameroon.

\section{References}

[1] (2010) Energy Information System.

[2] Saidur, R., Masjuki, H.H. and Jamaluddin, M.Y. (2007) An Application of Energy and Exergy Analysis in Residential Sector of Malaysia. Energy Policy, 35, 1050-1063. http://dx.doi.org/10.1016/j.enpol.2006.02.006

[3] Moran, M. (1982) Availability Analysis: A Guide to Efficient Energy Use. Prentice-Hall, Upper Saddle River.

[4] Reistad, G. (1975) Available Energy Conversion and Utilization in the United States. Journal of Energy Power, 97, 429-434.

[5] Wall, G., Sciubba, E. and Naso, V. (1994) Exergy Use in the Italian Society. Energy-The International Journal, 19, 1267-1274.

[6] Ozdogan, O. and Arikol, M. (1995) Energy and Exergy Analyses of Selected Turkish Industries. Energy, 20, 73-80. http://dx.doi.org/10.1016/0360-5442(94)00054-7

[7] Hammond, G.P. and Stapleton, A.J. (2001) Exergy Analysis of the United Kingdom Energy System. IMech-Journal of Power and Energy, 215, 141-162. http://dx.doi.org/10.1243/0957650011538424

[8] Ertesvag, I.S. and Mielnik, M. (2000) Exergy Analysis of the Norwegian Society. Energy, 25, 957-973. http://dx.doi.org/10.1016/S0360-5442(00)00025-6

[9] Xi, J. and Chen, G.Q. (2005) Exergy Analysis of Energy Utilization in the Transportation Sector in China. Energy Policy, 34, 1709-1719.

[10] Dincer, I., Hussain, M. and Al-Zaharnah, I. (2004) Analysis of Sectoral Energy and Exergy Use of Saudi Arabia. International Journal of Energy Research, 28, 205-243. http://dx.doi.org/10.1002/er.962

[11] Dincer, I., Hussain, M.M. and Al-Zaharnah, I. (2004) Energy and Exergy Utilization in Transportation Sector of Saudi Arabia. Applied Thermal Engineering, 24, 525-538. http://dx.doi.org/10.1016/j.applthermaleng.2003.10.011

[12] Dincer, I., Hussain, M.M. and Al-Zaharnah, I. (2004) Energy and Exergy Use in Public and Private Sector of Saudi Arabia. Energy Policy, 32, 1615-1624. http://dx.doi.org/10.1016/S0301-4215(03)00132-0

[13] Ertesvag, I.S. (2005) Energy, Exergy, and Extended-Exergy Analysis of the Norwegian Society 2000. Energy, 30, 649-675. http://dx.doi.org/10.1016/j.energy.2004.05.025

[14] Al-Ghandoor, A., Al-Hinti, I., Akash, B. and Abu-Nada, E. (2008) Analysis of Energy and Exergy Use in the Jordanian Urban Residential Sector. International Journal of Exergy, 5, 413-428.

[15] Szargut, J., Morris, D. and Steward, R. (1988) Exergy Analysis of Thermal, Chemical, and Metallurgical Processes. Hemisphere Publishing Corporation, New York.

[16] Petchers, N. (2003) Combined Heating, Cooling and Power Handbook: Technologies and Application. The Fairmont Press, Lilburn.

[17] Utlu, Z. and Hepbasli, A. (2007) A Review on Analyzing and Evaluating the Energy Utilization Efficiency of Countries. Renewable and Sustainable Energy Reviews, 11, 1-29. http://dx.doi.org/10.1016/j.rser.2004.12.005

[18] Utlu, Z. and Hepbasli, A. (2005) Analysis of Energy and Exergy Use of the Turkish Residential-Commercial Sector. Building and Environment, 40, 641-655. http://dx.doi.org/10.1016/j.buildenv.2004.08.006

[19] Utlu, Z. and Hepbasli, A. (2003) A Study on the Evaluation of Energy Utilization Efficiency in the Turkish Residential-Commercial Sector Using Energy and Exergy Analyses. Energy and Buildings, 35, 1145-1153. 
http://dx.doi.org/10.1016/j.enbuild.2003.09.003

[20] Rosen, M.A. and Dincer, I. (1997) Sectoral Energy and Exergy Modeling of Turkey. Transaction ASME, 119, $200-204$.

[21] Ileri, A. and Gurer, T. (1998) Energy and Exergy Utilization in Turkey during 1995. Energy, 23, 1099-1106. http://dx.doi.org/10.1016/S0360-5442(98)00063-2 